\title{
Nanocomposite Edible Films from Mango Puree Reinforced with Cellulose Nanofibers
}

\author{
Henriette M.C. Azeredo, Luiz Henrique C. Mattoso, Delilah Wood, Tina G. Williams, \\ Roberto J. Avena-Bustillos, AND TARa H. MCHugh
}

\begin{abstract}
Cellulose nanoreinforcements have been used to improve mechanical and barrier properties of biopolymers, whose performance is usually poor when compared to those of synthetic polymers. Nanocomposite edible films have been developed by adding cellulose nanofibers (CNF) in different concentrations (up to $36 \mathrm{~g} / 100 \mathrm{~g}$ ) as nanoreinforcement to mango puree based edible films. The effect of CNF was studied in terms of tensile properties, water vapor permeability, and glass transition temperature $\left(T_{\mathrm{g}}\right)$ of the nanocomposite films. CNF were effective in increasing tensile strength, and its effect on Young's modulus was even more noticeable, especially at higher concentrations, suggesting the formation of a fibrillar network within the matrix. The addition of CNF was also effective to improve water vapor barrier of the films. Its influence on $T_{\mathrm{g}}$ was small but significant. The study demonstrated that the properties of mango puree edible films can be significantly improved through CNF reinforcement.
\end{abstract}

Keywords: edible film, food packaging, mechanical properties, nanofibers, nanotechnology

\section{Introduction}

$\mathrm{F}$ ood and beverage packaging is responsible for about $70 \%$ of the packaging market in the United States, and more than half the worldwide market (Stevens 2002). This large volume of food packaging is meant to be quickly discarded, and the waste volume has not been greatly reduced by the recycling programs, because of high recycling costs and difficulties related to polymer separation (Azapagic and others 2003).

Several edible materials have had their film-forming properties studied, to produce edible films to be used in food packaging, not to completely replace synthetic plastics, but rather to improve their efficiency, thus reducing the amount of synthetic polymers required for each application. Fruit and vegetable purees and concentrates have been recently studied as film-forming edible materials (McHugh and others 1996; McHugh and Senesi 2000; Senesi and McHugh 2002; Rojas-Graü and others 2006, 2007). Such application of fruit and vegetable purees is related to the presence of polysaccharides in their composition, such as pectin, starch, and cellulose derivatives (Kaya and Maskan 2003). Edible films produced from fruit purees can combine the mechanical and barrier properties from the film-forming components with the color and flavor provided by the pigments and volatile compounds of the fruit. Moreover, the production of edible films is an interesting and promising way of using coproducts of fruit processing.

The commercial use of edible films has been limited because of problems related to their usually poor mechanical and barrier properties when compared to synthetic polymers. Several composites have been developed by adding reinforcing compounds

MS 20090101 Submitted 2/3/2009, Accepted 3/25/2009. Author Azeredo is with EMBRAPA Tropical Agroindustry, R. Dra. Sara Mesquita, 2270, CEP 60511-110, Fortaleza/CE, Brazil. Author Mattoso is with Natl. Nanotechnology Lab. for Agriculture-LNNA, EMBRAPA Agricultural Instrumentation, R. XV de Novembro, 1452, CEP 13560-970, São Carlos/SP, Brazil. Authors Wood, Williams, Avena-Bustillos, and McHugh are with Agricultural Research Service, Western Regional Research Center, 800 Buchanan St., Albany, CA, 94710, U.S.A. Author Avena-Bustillos is also with Dept. of Biological and Agricultural Engineering, 2030 Bainer Hall, Univ. of California, One Shields Ave., Davis, CA, 95616, U.S.A. Direct inquiries to author Azeredo (E-mail: ette@cnpat.embrapa.br).

(C) 2009 Institute of Food Technologists ${ }^{\circledR}$ doi: 10.1111/j.1750-3841.2009.01186.x Further reproduction without permission is prohibited (fillers) to polymers to enhance their thermal, mechanical, and barrier properties. However, many reinforced materials present poor adhesion at the interface of their components. Macroscopic reinforcing components often contain defects, which become less important as the particles of the reinforcing component are smaller (Ludueña and others 2007). The application of nanotechnology to edible polymers may open new possibilities for improving not only the properties but also the cost-price efficiency (Sorrentino and others 2007). The use of fillers that have at least 1 dimension in the nanometric range (nanoparticles) produces polymer nanocomposites (Alexandre and Dubois 2000). A uniform dispersion of nanoparticles leads to a very large matrix/filler interfacial area, which changes the molecular mobility, the relaxation behavior, and the consequent thermal and mechanical properties of the material. High aspect ratio fillers are particularly interesting because of their high specific surface area, providing better reinforcing effects (Azizi Samir and others 2005; Dalmas and others 2007).

Cellulose is a highly strong natural polymer. Cellulose nanofibers are an attractive class of nanomaterials for elaboration of low cost, lightweight, and high-strength nanocomposites (Helbert and others 1996; Podsiadlo and others 2005). In plants or animals, the cellulose chains are synthesized to form nanofibers, which are bundles of molecules that are elongated and stabilized through hydrogen bonding (Azizi Samir and others 2005; Wang and Sain 2007). Nanofibers are nanosized in diameters (2 to $20 \mathrm{~nm}$, depending on the origin), and lengths ranging from a few hundred up to thousands of nanometers (Azizi Samir and others 2005; Oksman and others 2006).

This study was the first to evaluate the effect of different concentrations of cellulose nanofibers added as a nanoreinforcing component on tensile properties, water vapor permeability and glass transition temperature of mango puree edible films.

\section{Materials and Methods}

\section{Mango-puree solution formulation and film casting}

The mango puree (29\% total solids, $27.5 \%$ soluble solids) was obtained from Keitt mangoes. The cellulose nanofibers (CNF,

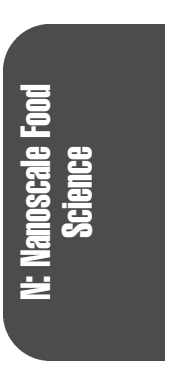

Vol. 74, Nr. 5, 2009-JOURNAL OF FOOD SCIENCE N31 
Novacel ${ }^{\circledR}$ PH-101) were provided by FMC BioPolymer (Philadelphia, Pa., U.S.A.).

An aliquot of the CNF suspension was mixed with an equal volume of $2 \%$ uranyl acetate (UA). A $10 \mu \mathrm{L}$ drop of the UA-fibril mixture was dispensed onto a 400-mesh copper grid, allowed to stand for 30 to $60 \mathrm{~s}$, and the excess fluid was wicked off with Whatman $\mathrm{nr} 1$ filter paper. The grid was air dried and viewed in a CM12 scanning transmission electron microscope (STEM) (FEI Co. Inc., Hillsboro, Oreg., U.S.A.) operating in the bright field mode at $80 \mathrm{kV}$. Digita images were captured with the STEM's associated XR41 CCD camera system (AMT, Danvers, Mass., U.S.A.). Fiber lengths and widths were measured directly from transmission electron micrographs using Image Pro Plus 6.3 (Media Cybernetics Inc., Bethesda, Md., U.S.A.). Data were collected and analyzed using Microsoft Exce 2003 (Microsoft, Redmond, Wash., U.S.A.)

Different concentrations of CNF (ranging from 1 to $36 \mathrm{~g}$ per 100 $\mathrm{g}$ of mango puree, on a dry basis) were added to the mango puree and the dispersions were homogenized at $6500 \mathrm{rpm}$ for $30 \mathrm{~min}$, using a Polytron PT 3000 (Brinkmann Instruments, Westbury, N.Y. U.S.A.). A control film was elaborated only with mango puree. The film-forming dispersions were submitted to vacuum to remove bubbles, and films were cast on leveled $29 \times 29 \mathrm{~cm}$ square plates ( 45 g per plate) and allowed to dry for $16 \mathrm{~h}$ at $22{ }^{\circ} \mathrm{C}$ and $42 \% \mathrm{RH}$. Samples of the dried films were cut and peeled from the casting surface, and stored under refrigeration until analyses.

\section{Analyses on mango puree edible films}

Film thicknesses were measured with a micrometer IP 65 (Mitutoyo Manufacturing, Tokyo, Japan) to the nearest $0.001 \mathrm{~mm}$, at 7 to 8 random positions around the film for samples designed for water vapor permeability (WVP) and tensile tests.

Tensile properties (tensile strength [TS], elongation at break [EB], and Young's modulus [YM]) were measured according to standard method D882-97 (ASTM 1997), using an Instron Mode 55R4502 Universal Testing Machine (Instron, Canton, Mass., U.S.A.) with a $100 \mathrm{~N}$ load cell. The gravimetric modified cup method (McHugh and others 1993) based on standard method E96-80 (ASTM 1989) was used to determine WVP. The detailed methods for both WVP and tensile tests were described by Rojas-Graü and others (2007).

The glass transition temperature $\left(T_{\mathrm{g}}\right)$ of the nanocomposite films was measured by differential scanning calorimetry (DSC) using an mDSC 2910 (TA Instruments, New Castle, Del., U.S.A.). The DSC profiles were run from -40 to $40{ }^{\circ} \mathrm{C}$, at a heating rate of $10^{\circ} \mathrm{C} / \mathrm{min}$

Eight specimens of mango puree edible film from each treatment were evaluated for measuring tensile properties and water vapor permeability. For $T_{\mathrm{g}}$ measurements, 4 specimens were evaluated.

The effect of CNF on physical properties was evaluated by comparing means of the properties of the films with different CNF concentrations by Tukey tests $(P<0.05)$.

The samples were prepared for scanning electron microscopy by dropping a $1 \mathrm{~cm}^{2}$ piece cut from the center of the film into liquid nitrogen and allowing the piece to equilibrate under the liquid nitrogen. The film piece was then fractured into several smaller pieces with a prechilled razor blade held in a vice grip. The smaller pieces were removed and placed immediately on filter paper and transferred to a desiccator for 30 to $60 \mathrm{~min}$. Selected smaller pieces were mounted individually edge-up on a small half stub which was in turn mounted to a full stub using double adhesive coated carbon tabs (Ted Pella, Inc, Redding, Calif., U.S.A.). The film samples were coated for 2 min with gold-palladium in a Denton Desk II sputter coating unit (Denton Vacuum, LLC, Moorestown, N.J., U.S.A.), and viewed and photographed in a Hitachi S4700 field emission scanning electron microscope (Hitachi, Tokyo, Japan).

\section{Results and Discussion}

Cellulose nanofibers are presented in Figure 1. Their average dimensions were: length, $(82.6 \pm 4.3) \mathrm{nm}$, and diameter, $(7.2 \pm 0.3) \mathrm{nm}$. Their aspect ratio (calculated by dividing fiber length by its diameter) was thus about 11.5. Their average diameter is within the range mentioned by other authors (8 to $10 \mathrm{~nm}$, according to Lima and Borsali [2004]; less than $10 \mathrm{~nm}$, according to Mathew and Dufresne [2002]). The average fiber length has been below the range reported in other studies (500 to $2000 \mathrm{~nm}$, according to Mathew and Dufresne [2002]; 100 to $300 \mathrm{~nm}$, according to Lima and Borsali [2004]), resulting in lower aspect ratios. Still, the average aspect ratio of the fibers has been higher than 10, considered as the minimum value for a good stress transfer from the matrix to the fibers for any significant reinforcement to occur (Jiang and others 2007; Mutjé and others 2007).

Figure 2 presents the ultrastructure of films produced from pure mango puree (control) and from puree with a CNF loading of $36 \mathrm{~g} / 100 \mathrm{~g}$ ( $36 \mathrm{~g}$ of CNF per $100 \mathrm{~g}$ of mango puree). The nanofibers (appearing as lighter regions in Figure 2B) seem to have presented good interactions with the mango puree (darker regions). They were well dispersed in the matrix, without significant agglomeration. Interactions may have occurred between cellulose and neutral sugar side chains of mango pectin, as suggested in previous studies (Oechslin and others 2003; Vignon and others 2004; Zykwinska and others 2005). Zykwinska and others (2005) mentioned that, although there is little information about how pectin interacts with cellulose, it is likely that such interactions are mediated by hydrogen bonds. Moreover, the hydrophilic sites of mango starch may have also interacted with hydroxyl groups of cellulose (Averous and others 2001; Wu and others 2009) by hydrogen bonds (Chen and others 2009).

Table 1 presents physical properties of mango puree films containing different CNF concentrations. CNF were effective in

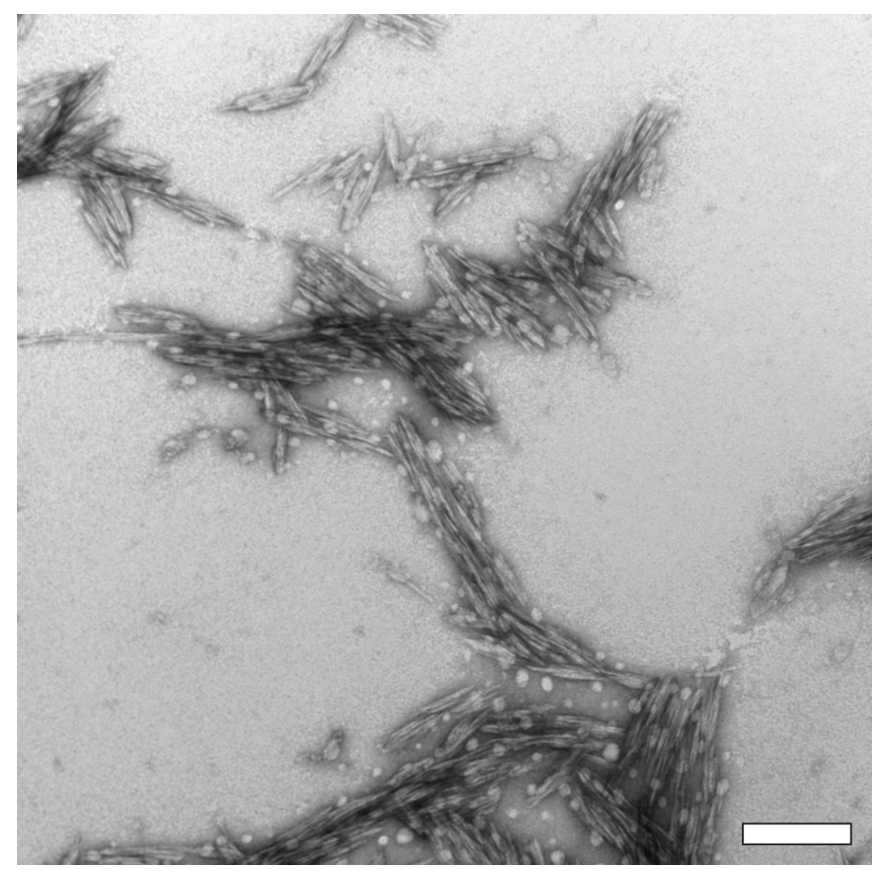

Figure 1-Cellulose nanofibers visualized by TEM. Scale bar $=200 \mathrm{~nm}$ 
increasing tensile strength (at concentrations of $2 \mathrm{~g} / 100 \mathrm{~g}$ or more) and Young's modulus (at concentrations $\geq 5 \mathrm{~g} / 100 \mathrm{~g}$ ). The elongation at break was not significantly impaired at CNF concentrations up to $10 \mathrm{~g} / 100 \mathrm{~g}$, while films with higher CNF concentrations presented decreased elongation when compared to the control. Figure 3 presents typical stress-strain curves obtained from mango puree edible films without CNF (control) and with CNF loadings of $10 \mathrm{~g} / 100 \mathrm{~g}$ and $36 \mathrm{~g} / 100 \mathrm{~g}$ (CNF10 and CNF36, respectively). Addition of CNF changed the stress-strain behavior showing mixed deformation mechanisms. The films CNF10 and CNF36 show yield stress at $3 \%$ elongation. Below this yield, those films followed a reversible elastic deformation with sharply increased elastic modulus compared with that of control film. Addition of CNF increased the elastic modulus of the films. At more than 3\% elongation, those films were deformed irreversibly showing plasticity behaviors, while control film did not show any yield as indicated with a simple straight slope. After yield, the slopes of CNF10 and CNF36 did not show a significant difference. Also, when a 3\% tensile deformation is reached, all cross-linkings made by CNF are already destroyed, and after the fracture of the nanofibers, CNF10 and CNF36 films show the same deformation mechanisms, which mainly happened at the amorphous area by the stretching and sliding of polymer molecules. Both tensile strength and elastic modulus of the nanocomposites were improved when compared to those of the neat mango puree matrix, corroborating several previous findings (Ljungberg and others 2005; Lu and others 2005; Dogan and McHugh 2007; Wang and Sain 2007; Tang and Liu 2008; Kim and others 2009). On the other hand, the effect of CNF on elongation depended on the loading of CNF. A loading of $10 \mathrm{~g} / 100 \mathrm{~g}$ did not affect elongation, but when the loading was increased to $36 \mathrm{~g} / 100 \mathrm{~g}$, the elongation was impaired. Such a decreased elongation with high loading of CNF suggests a poor interaction between nanofibers and the mango puree matrix, as suggested by Kim and Jo (2009), although the good dispersion of the nanofibers (Figure 2) indicates a good interaction between the film components even with a CNF loading of $36 \mathrm{~g} / 100 \mathrm{~g}$. Zimmermann and others (2004) observed that, although a sharp rise has occurred in elongation with a loading of up to $5 \mathrm{~g} / 100 \mathrm{~g}$ of nanofibers, higher loadings ( 10 to $20 \mathrm{~g} / 100 \mathrm{~g}$ ) resulted in decreased elongation. Other researchers also reported decreased elongation with addition of

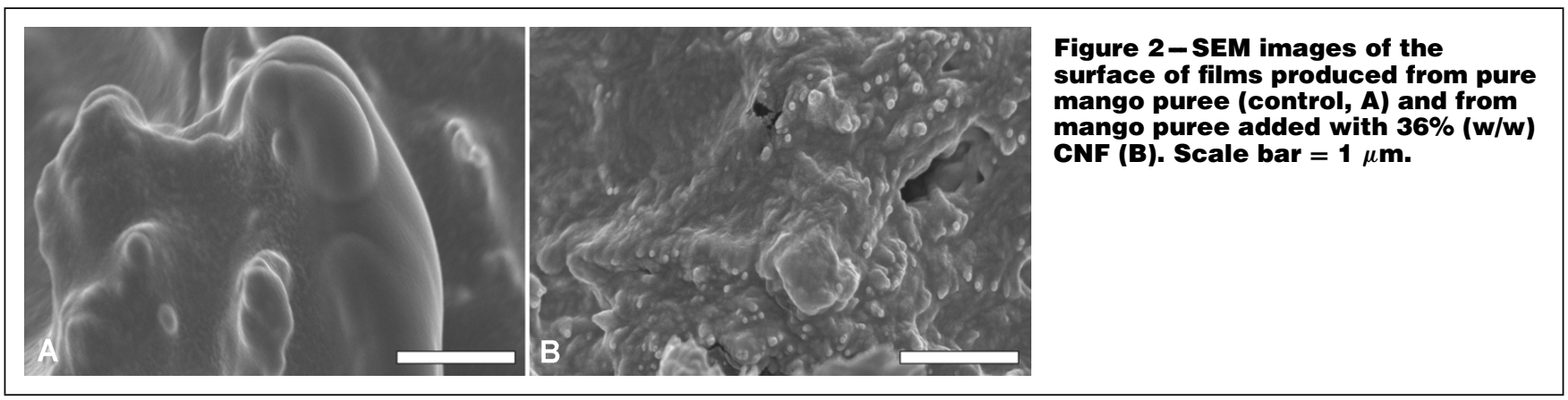

Table 1 - Physical properties of mango puree edible films with different concentrations of CNF nanoreinforcements.

\begin{tabular}{|c|c|c|c|c|c|}
\hline CNF $(g / 100 g)^{A}$ & TS (MPa) & EB (\%) & YM (MPa) & WVP (g.mm/kPa.h.m²) & $T_{\mathrm{g}}\left({ }^{\circ} \mathrm{C}\right)$ \\
\hline 0 & $(4.09 \pm 0.12)^{\mathrm{e}}$ & $(44.07 \pm 0.98)^{\mathrm{a}}$ & $(19.85 \pm 0.51)^{\mathrm{e}}$ & $(2.66 \pm 0.06)^{a}$ & $(-10.63 \pm 0.47)^{\mathrm{e}}$ \\
\hline 1 & $(4.24 \pm 0.25)^{\mathrm{de}}$ & $(42.42 \pm 1.90)^{a b}$ & $(21.55 \pm 0.98)^{\mathrm{e}}$ & $(2.40 \pm 0.19)^{\mathrm{ab}}$ & $(-8.51 \pm 0.46)^{d}$ \\
\hline 2 & $(4.42 \pm 0.14)^{\mathrm{de}}$ & $(43.30 \pm 1.46)^{\mathrm{ab}}$ & $(22.56 \pm 0.88)^{\mathrm{e}}$ & $(2.17 \pm 0.08)^{b c}$ & $(-8.57 \pm 0.33)^{d}$ \\
\hline 5 & $(4.58 \pm 0.21)^{c d}$ & $(41.79 \pm 0.44)^{b}$ & $(30.93 \pm 1.27)^{\mathrm{d}}$ & $(2.16 \pm 0.05)^{\mathrm{bc}}$ & $(-7.72 \pm 0.26)^{\mathrm{c}}$ \\
\hline 10 & $(4.91 \pm 0.13)^{c}$ & $(43.19 \pm 1.73)^{\mathrm{ab}}$ & $(40.88 \pm 1.41)^{c}$ & $(2.03 \pm 0.11)^{c}$ & $(-6.81 \pm 0.36)^{b}$ \\
\hline 18 & $(5.54 \pm 0.07)^{\mathrm{b}}$ & $(39.8 \pm 0.53)^{b}$ & $(78.82 \pm 5.00)^{b}$ & $(1.90 \pm 0.06)^{\mathrm{cd}}$ & $(-5.88 \pm 0.25)^{\mathrm{a}}$ \\
\hline 36 & $(8.76 \pm 0.11)^{\mathrm{a}}$ & $(31.54 \pm 2.29)^{c}$ & $(322.05 \pm 19.43)^{a}$ & $(1.67 \pm 0.11)^{d}$ & $(-6.04 \pm 0.17)^{\mathrm{a}}$ \\
\hline
\end{tabular}

AMass of CNF added to $100 \mathrm{~g}$ of mango puree, on a dry basis. TS = tensile strength (MPa); $\mathrm{EB}=$ elongation at break (\%); YM = Young's modulus (MPa); $\mathrm{WVP}=$ water vapor permeability (g.mm/kPa.h. $\left.\mathrm{m}^{2}\right) ; T_{\mathrm{g}}=$ glass transition temperature $\left({ }^{\circ} \mathrm{C}\right)$. Means in same column with different letters are significantly different at $P<0.05$

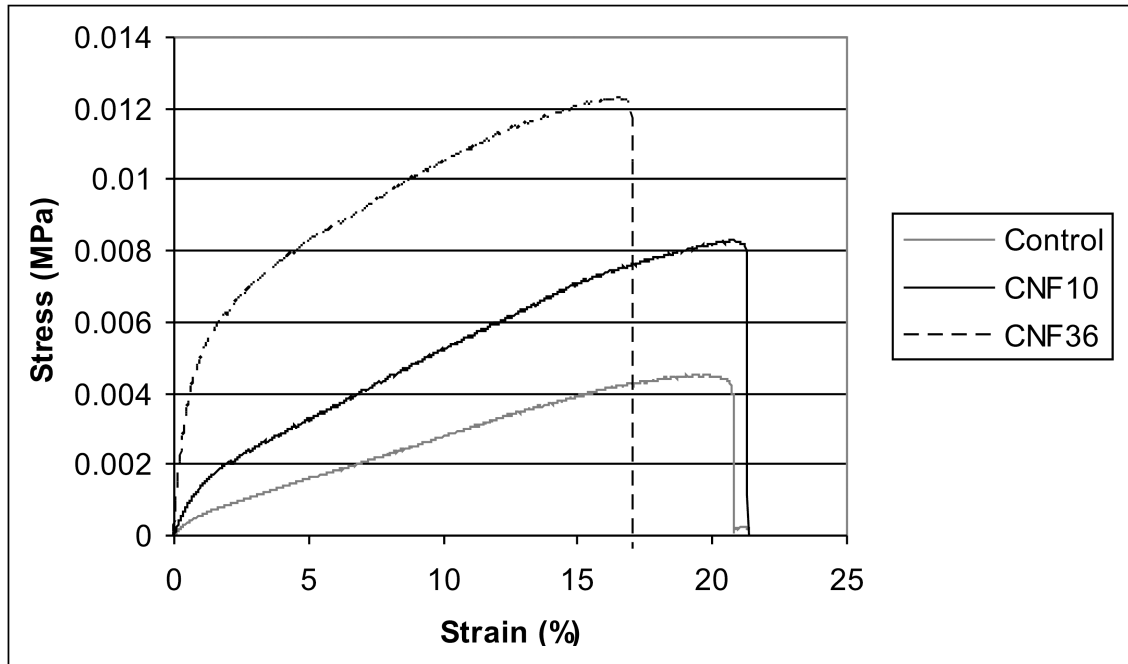

Figure 3-Typical stress-strain curves from mango puree edible films without CNF (control) and with CNF loadings of $10 \mathrm{~g} / 100 \mathrm{~g}$ (CNF10) and $36 \mathrm{g7/100} \mathrm{g}$ (CNF36). 
cellulose nanofibers (Azizi Samir and others 2004; Ljungberg and others 2006; Leitner and others 2007; Roohani and others 2008; Tang and Liu 2008). In this study, the property most affected by CNF concentration was the modulus, which increased more than $100 \%$ when with a CNF loading of $10 \mathrm{~g} / 100 \mathrm{~g}$, and more than $1500 \%$ with a loading of $36 \mathrm{~g} / 100 \mathrm{~g}$. Other researchers (Helbert and others 1996; Wu and others 2007) observed similarly high (or even higher) influence of CNF on modulus of polymeric films. According to Helbert and others (1996), such a great effect is ascribed to the formation of a fibrillar network within the polymer matrix, the cellulose fibers being probably linked through hydrogen bonds. Zimmermann and others (2004) observed that nanofiber contents of up to $5 \mathrm{~g} / 100 \mathrm{~g}$ resulted in no strength or stiffness improvement of poly(vinyl alcohol) composites, and they suggested that probably a minimum nanofiber content is required to induce intense interactions between nanofibers and thus the formation of networks.

WVP of the control film was comparable to the value $(2.23 \mathrm{~g} . \mathrm{mm} /$ kPa.h. $\mathrm{m}^{2}$ ) reported by Hoagland and Parris (1996) for pectin films plasticized with lactic acid, suggesting that the polysaccharide content of the mango puree was high enough to produce a film with a fairly good water vapor barrier. The addition of at least $10 \mathrm{~g}$ of CNF per $100 \mathrm{~g}$ of matrix was effective to decrease WVP of mango puree films, similar to results reported by Paralikar and others (2008) and Sanchez-Garcia and others (2008), by addition of cellulose nanofibers to other polymeric films. Different results were reported by Dogan and McHugh (2007), who have observed no significant changes in WVP of hydroxyl propyl methyl cellulose (HPMC) films by CNF addition (in loadings up to $25 \mathrm{~g} / 100 \mathrm{~g}$ ). The presence of crystalline fibers is thought to increase the tortuosity in the materials leading to slower diffusion processes and, hence, to lower permeability (Sanchez-Garcia and others 2008). The barrier properties are enhanced if the filler is less permeable, and have good dispersion in the matrix and a high aspect ratio (Lagaron and others 2004). In the present study, the interactions of CNF with mango components (mainly pectin and/or starch) as well as the interactions between nanofibers may have favored the water vapor barrier.

Since the soluble solid content of the mango puree used in this study was $27.5 \%$, and considering that most soluble solids in mango composition are mono- and disaccharides (Medlicott and Thompson 1985), the very low $T_{\mathrm{g}}$ of the films is ascribed to the plasticizing effect of these sugars (Ghanbarzadeh and others 2006). Sub-zero $T_{\mathrm{g}}$ values, on the one hand, suggest a relatively poor chemical stability of the films, because of the high molecular mobility (and consequently high reactivity) of its components. On the other hand, such low $T_{\mathrm{g}}$ values imply a very good flexibility of the films even at refrigeration temperatures, which is an advantage concerning the potential use of the material in food packaging applications. Although $T_{\mathrm{g}}$ increases have been small with CNF incorporation, it was significant (Table 1). Some other authors (Psomiadou and others 1996; Anglès and Dufresne 2000; Borges and others 2001; Petersson and Oksman 2006; Alemdar and Sain 2008) reported increases in $T_{\mathrm{g}}$ of biopolymer films by addition of cellulose nanofibers. The increased $T_{\mathrm{g}}$ with CNF incorporation may be ascribed to one or more of the following CNF effects: (1) cellulose-water interactions involve a redistribution of water molecules within the matrix, decreasing the plasticization effect of water (Anglès and Dufresne 2000; Roohani and others 2008; Song and Zheng 2009); (2) interactions between the matrix components and CNF result in a decrease in mobility of the matrix (Lu and others 2005; Song and Zheng 2009); (3) CNF themselves promote an increased crystallinity (and consequently a restricted mobility) of the matrix (Mathew and Dufresne 2002; Aziz Samir and others 2004).

\section{Conclusions}

he cellulose reinforcement was well dispersed into the mango puree matrix. The performance of mango puree edible films was noticeably improved by CNF reinforcement. Mechanical properties, except elongation, were improved by the addition of cellulose nanofibers to mango puree edible films. The elastic modulus was the most drastically affected property. Elongation was not impaired at CNF concentrations up to $10 \mathrm{~g} / 100 \mathrm{~g}$. The water vapor permeability was significantly decreased when CNF was incorporated at loadings of at least $10 \mathrm{~g} / 100 \mathrm{~g}$. The effect of the filler on glass transition temperature was low but significant.

\section{Acknowledgments}

The authors gratefully acknowledge the financial support given by CNPq, FINEP, and ARS/Embrapa-Labex program. They would like also to extend their most sincere appreciation to Peter H. Cooke (Agricultural Research Service, Eastern Regional Research Center, Wyndmoor, Pa., U.S.A.), for his helpful assistance in the image analyses, as well to FMC, for having provided several samples of cellulose nanofibers for the experiment. The 1st author thanks EMBRAPA for the scholarship provided, and the Processed Food Research unit of the USDA for their support to this study.

\section{References}

Alemdar A, Sain M. 2008. Biocomposites from wheat straw nanofibers: morphology, thermal and mechanical properties. Compos Sci Technol 68:557-65.

Alexandre M, Dubois P. 2000. Polymer-layered silicate nanocomposites: preparation, properties and uses of a new class of materials. Mater Sci Eng 28:1-63.

Anglès MN, Dufresne A. 2000. Plasticized starch/tunicin whiskers nanocomposites. 1. Structural analysis. Macromol 33(22):8344-53.

ASTM. 1989. Standard test methods for water vapor transmission of materials. E9692. In: Annual book of American Standard Testing Methods. Philadelphia, Pa.: ASTM

ASTM. 1997. Standard test method for tensile properties of thin plastic sheeting. D882. In: Annual book of American Standard Testing Methods. Philadelphia, Pa.: ASTM.

Averous L, Fringant C, Moro L. 2001. Plasticized starch-cellulose interactions in polysaccharide composites. Polymer 42(15):6565-72.

Azapagic A, Emsley A, Hamerton I. 2003. Polymers-the environment and sustainable development. New York: Wiley \& Sons. 234 p.

development. New York: Wiley \& Sons. 234 p.
Azizi Samir MAS, Alloin F, Sanchez JY, Dufresne A. 2004. Cellulose nanocrystals reinforced poly(oxyethylene). Polymer 45:4149-57.

Azizi Samir MAS, Alloin F, Dufresne A. 2005. Review of recent research into cellulosic whiskers, their properties and their application in nanocomposite field. Biomacromol 6(2):612-26.

Ghanbarzadeh B, Oromiehie AR, Mousavi M, Emam Djomeh Z, Razmirad E, Milani J. 2006. Effect of plasticizing sugars on rhelogical and thermal properties of zein resins and mechanical properties of zein films. Food Res Int 39:882-90.

Borges JP, Godinho MH, Martins AF, Trindade AC, Belgacem MN. 2001. Cellulosebased composite films. Mech Compos Mater 37(3):257-64.

based composite films. Mech Compos Mater 37(3):257-64.
Chen Y, Liu C, Chang PR, Cao X, Anderson DP. 2009. Bionanocomposites based on pea starch and cellulose nanowhiskers hydrolyzed from pea hull fibre: effect of hydrolysis time. Carbohydr Polym 76(4):607-15.

Dalmas F, Cavaillé JY, Gauthier C, Chazeau L, Dendievel R. 2007. Viscoelastic behavior and electrical properties of flexible nanofiber filled polymer nanocomposites. Influence of processing conditions. Compos Sci Technol 67:829-39.

Dogan N, McHugh TH. 2007. Effects of microcrystalline cellulose on functional properties of hydroxyl propyl methyl cellulose microcomposite films. J Food Sci 72(1):E16-22.

Helbert W, Cavaillé JY, Dufresne A. 1996. Thermoplastic nanocomposites filled with wheat straw cellulose whiskers. Part I: processing and mechanical behavior. Polym Compos 17(4):604-11.

Hoagland PD, Parris N. 1996. Chitosan/pectin laminated films. J Agric Food Chem 44:1915-9.

iang B, Liu C, Zhang C, Wang B, Wang Z. 2007. The effect of non-symmetric distribution of fiber orientation and aspect ratio on elastic properties of composites. Compos B Eng 38:24-34

Kaya S, Maskan A. 2003. Water vapour permeability of pestil (a fruit leather) made from boiled grape juice with starch. J Food Eng 57(3):295-9.

Kim KH, Jo WH. 2009. A strategy for enhancement of mechanical and electrical properties of polycarbonate/multi-walled carbon nanotube composites. Carbon 47(4):1126-34.

Kim Y Jung R, Kim HS, Jin HJ. 2009. Transparent nanocomposites prepared by incorporating microbial nanofibrils into poly(L-lactic acid). Curr Appl Phys 9(1):S69-71. porating microbial nanofibrils into poly(L-lactic acid). Curr Appl Phys 9(1):S69-71.
Lagaron JM, Catalá R, Gavara R. 2004. Structural characteristics defining high-barrier polymeric materials. Mater Sci Technol 20:1-7.

Leitner J, Hinterstoisser B, Wastyn M, Keckes J, Gindl W. 2007. Sugar beet cellulose nanofibril-reinforced composites. Cellulose 14:419-25.

Lima MMS, Borsali R. 2004. Rod-like cellulose microcrystals: structure, properties, and applications. Macromol Rapid Commun 25:771-87. 
Ljungberg N, Bonini C, Bortolussi F, Boisson C, Heux L, Cavaillé JY. 2005. New nanocomposite materials reinforced with cellulose whiskers in atactic polypropylene: effect of surface and dispersion characteristics. Biomacromolecules 6(5):2732-9.

Ljungberg N, Cavaillé JY, Heux L. 2006. Nanocomposites of isotactic polypropylene reinforced with rod-like cellulose whiskers. Polymer 47(18):6285lene.

Lu Y, Weng L, Cao X. 2005. Biocomposites of plasticized starch reinforced with cellulose crystallites from cottonseed linter. Macromol Biosci 5:1101-7.

Ludueña LN, Alvarez VA, Vasquez A. 2007. Processing and microstructure of PCL/clay nanocomposites. Mater Sci Eng A 460-461:121-9.

Mathew AP, Dufresne A. 2002. Morphological investigation of nanocomposite from sorbitol plasticized starch and tunicin whiskers. Biomacromol 3(3):60917.

McHugh TH, Avena-Bustillos RJ, Krochta JM. 1993. Hydrophilic edible film: modified procedure for water vapor permeability and explanation of thickness effects. J Food Sci 58(4):899-903.

McHugh TH, Senesi E. 2000. Apple wraps: a novel method to improve the quality and extend the shelf life of fresh-cut apples. J Food Sci 65(3)480-5.

McHugh TH, Huxsoll CC, Krochta JM.1996. Permeability properties of fruit puree edible films. J Food Sci 61(1):88-91.

Medlicott AP, Thompson AK. 1985. Analysis of sugars and organic acids in ripening mango fruits (Mangifera indica $\mathrm{L}$. var Keitt) by high performance liquid chromatography. J Sci Food Agric 36(7):561-6.

Mutjé P, Lopez A, Vallejos ME, Lopez JP, Vilaseca F. 2007. Full exploitation of Cannabis sativa as reinforcement/filler of thermoplastic composite materials. Compos A Appl Sci Manuf 38(2):369-77.

Oechslin R, Lutz MV, Amado R. 2003. Pectic substances isolated from apple cellulosic residue: structural characterisation of a new type of rhamnogalacturonan. I. Carbohydr Polym 51:301-10.

Oksman K, Mathew AP, Bondeson D, Kvien I. 2006. Manufacturing process of cellulose whiskers/polylactic acid nanocomposites. Compos Sci Technol 66(15):277684

Paralikar SA, Simonsen J, Lombardi J. 2008. Poly(vinyl alcohol)/cellulose nanocrystal barrier membranes. J Memb Sci 320(1-2):248-58.

Petersson L, Oksman K. 2006. Biopolymer based nanocomposites: Comparing layered silicates and microcrystalline cellulose as nanoreinforcement. Compos Sci Technol 66:2187-96.

Podsiadlo P, Choi SY, Shim B, Lee J, Cuddihy M, Kotov NA. 2005. Molecularly engineered nanocomposites: layer-by-layer assembly of cellulose nanocrystals. Biomacromolecules 6:2914-8.
Psomiadou E, Arvanitoyannis I, Yamamoto N. 1996. Edible films made from natura resources; microcrystalline cellulose (MCC), methylcellulose (MC) and corn starch and polyols-Part 2. Carbohydr Polym 31:193-204.

Rojas-Graü MA, Avena-Bustillos RJ, Friedman M, Henika PR, Martín-Belloso O, McHugh TH. 2006. Mechanical, barrier, and antimicrobial properties of apple puree edible films containing plant essential oils. J Agric Food Chem 54:9262-7.

Rojas-Graü MA, Avena-Bustillos RJ, Olsen C, Friedman M, Henika PR, Martín-Belloso O, Pan Z, McHugh TH. 2007. Effects of plant essential oil compounds on mechanical, barrier and antimicrobial properties of alginate-apple puree edible films. J Food Eng 81:634-41.

Roohani M, Habibi Y, Belgacem NM, Ebrahim G, Karimi AN, Dufresne A. 2008. Cellulose whiskers reinforced polyvinyl alcohol copolymers nanocomposites. Eur Polym J 44:2489-98.

Sanchez-Garcia MD, Gimenez E, Lagaron JM. 2008. Morphology and barrier properties of solvent cast composites of thermoplastic biopolymers and purified cellulose fibers. Carbohydr Polym 71:235-44.

Senesi E, McHugh TH. 2002. Film e coperture eduli com matrici a base di fruta. Ind Aliment 41(420):1289-94.

Song Y, Zheng Q. 2009. Structure and properties of methylcellulose microfiber rein forced wheat gluten based green composites. Ind Crops Prod 29(2-3):446-54. Sorrentino A, Gorrasi G, Vittoria V. 2007. Potential perspectives of bionanocomposites for food packaging applications. Trends Food Sci Technol 18(2):84-95

Stevens ES. 2002. Green plastics: An introduction to the new science of biodegradable plastics. Princeton, N.J.: Princeton Univ. Press. 272 p.

Tang C, Liu H. 2008. Cellulose nanofiber reinforced poly(vinyl alcohol) composite film with high visible light transmittance. Compos A 39(10):1638-43.

Vignon MR, Heux L, Malainine ME, Mahrouz M. 2004. Arabinan-cellulose composite in Opuntia ficus-indica prickly pear spines. Carbohydr Res 339:123-31.

Wang B, Sain M. 2007. Isolation of nanofibers from soybean source and their reinforcing capability on synthetic polymers. Compos Sci Technol 67:2521-7.

Wu Q, Henriksson M, Liu X, Berglund LA. 2007. A high strength nanocomposite base on microcrystalline cellulose and polyurethane. Biomacromolecules 8:3687-92.

Wu RL, Wang XL, Li F, Li HZ, Wang YZ. 2009. Green composite films prepared from cellulose, starch and lignin in room-temperature ionic liquid. Biores Techno 100(9):2569-74.

Zimmermann T, Pöhler E, Geiger T. 2004. Cellulose fibrils for polymer reinforcement. Adv Eng Mater 6(9):754-61.

Zykwinska AW, Ralet MCJ, Garnier CD, Thibault JFJ. 2005. Evidence for in vitro binding of pectin side chains to cellulose. Plant Physiol 139:397-407. 